\title{
Effect of heat treatment on the microstructure and corrosion properties of cast duplex stainless steels
}

\author{
Aleksandr Fedorov ${ }^{1, *}$, Andrey Zhitenev ${ }^{1}$, Darya Strekalovskaya ${ }^{1}$ \\ ${ }^{1}$ Peter the Great St.Petersburg Polytechnic University, 195427, Polytechnicheskaya 29, Saint Petersburg, Russia
}

\begin{abstract}
The effect of the quenching temperature on the pitting corrosion resistance of lean duplex stainless steel (DSS) were examined. Using thermodynamic modeling of phase formation processes in steel during solidification and subsequent cooling was shown that the equal amount of austenite and ferrite is achieved at $1210^{\circ} \mathrm{C}$ for examined composition. Experimental steel samples were quenched from 1100 and $1200^{\circ} \mathrm{C}$. It was found that as the temperature rises, the pitting potential increases significantly due to the achievement of a favorable phase ratio. The results of this experimental study made it possible to develop a heat treatment that provides high corrosion properties of lean DSS.
\end{abstract}

\section{Introduction}

Recently, duplex stainless steels (DSSs) are being increasingly employed in chemical, petrochemical and energy industries [1-3]. DSSs have wide applications not only in the as-rolled form, but in the as-cast, in particular, in the cast parts of oil-pumping equipment [4]. The key feature of DSSs is containing equal fraction of ferritic and austenitic phases in their microstructure $[5,6]$, which should be ensured by the chemical composition and production technology.

Heat treatment is the key technology for casts, since in fact it is the only way to confer the required properties for the product. The most common type of heat treatment is quenching after isothermal annealing at temperatures of $1000-1100^{\circ} \mathrm{C}$ [1], aimed at dissolving the precipitation of secondary phases [4], achieving an optimal phase balance of austenite and ferrite [5] and reducing the level of chemical microheterogeneity [6], etc.

It is known that within the group or even grade, the chemical composition and the phase ratio can vary greatly, without reaching their optimum values for the combination of mechanical properties and corrosion resistance $[1,6,7]$. Earlier $[9,10]$, the temperature $T_{50 / 50}^{\gamma / \delta}$ was chosen as a criterion for choosing an alloy, at which ferritic and austenitic phases are in equal fraction. Also, in study was shown how changing the composition of steel and solving an optimization problem, it is able to control this criterion. But for manufacturers, the choice of grade or chemical composition in the grade is depends on the relationship between technological capabilities and economic feasibility. In fact, technologists are often forced to work with suboptimal chemical composition of steels, choosing a heat-treatment mode based only on empirical ideas about the processes occurring in steels, without taking into account the real chemical composition of the steel, its structure, and its effect on corrosion properties.

Therefore, the aim of this study was to determine the effect of the heat-treatment modes on the microstructure and corrosion resistance of lean DSS [1] to evaluate the heat-treatment mode for each composition.

\section{Materials and methods}

In this study were investigated 21 wt.\% Cr duplex steel as-cast and heat-treated (Table 1). The experimental steel was performed in the open induction furnace [8]. The raw materials used were high-purity electrical steel, metallic chromium, metallic nickel, ferromanganese-95 and ferromolybdenum-60. Heating and melting of the raw materials for 30-35 minutes, after which alloying and deoxidizing components were added to the furnace. The metal was kept in the furnace for 10 minutes, after which it was cast at $1485^{\circ} \mathrm{C}$ into a copper mold with a cross section of $40 \mathrm{~mm}$ and a height of $100 \mathrm{~mm}$. The chemical composition of the experimental steels was determined by spark optical emission spectroscopy. The content of sulfur and phosphorus in all steel samples did not exceed $0.01 \%$.

Table 1. Chemical composition of examined steel.

\begin{tabular}{|c|c|c|c|c|c|c|c|c|}
\hline \multicolumn{10}{|c|}{ Elements, wt-\% } \\
\hline $\mathbf{C}$ & $\mathbf{S i}$ & $\mathbf{M n}$ & $\mathbf{N i}$ & $\mathbf{M o}$ & $\mathbf{N}$ & $\mathbf{C u}$ & $\mathbf{T i}+\mathbf{N b}+\mathbf{V}$ & $\mathbf{C r}$ \\
\hline 0.02 & 0.6 & 1.6 & 6 & 0.50 & 0.05 & 0.17 & 0.06 & 21 \\
\hline
\end{tabular}

The samples of steel were heat treated in the programmable muffle furnace, heated to temperatures of 1100 and $1200^{\circ} \mathrm{C}$, held at each temperature for 60 minutes, and quenched with water. Metallographic studies were performed using optical microscopy methods. The study of the microstructure was investigated using the inverted Reichert-Jung MeF3 A microscope equipped

* Corresponding author: zhitenev ai@spbstu.ru 
with a Thixomet image analyzer. To reveal the microstructure was used electrochemical etching with a $50 \%$ solution of nitric acid.

Electrochemical tests were carried out according to the procedure detailed in [10] for at-cast and heat-treated samples. The pitting potential $E_{\text {pit }}$ was determined in accordance with the ISO 17475:2005 [9]. For measurements was used the test cell (Fig. 1), controlled by a VersaStat Princeton Applied Research potentiostat. The tests were carried out at room temperature in a 5\% $\mathrm{NaCl}$ solution with acetic acid at $\mathrm{pH}=3$.

The samples were polished, then copper wire conductors were soldered to them and the entire surface was insulated with coating of a mixture of wax and rosin, except an uninsulated working space on the polished surface. The samples were immersed in a test cell and held for 55 minutes to achieve the equilibrium corrosion potential $\left(E_{\text {cor }}\right)$. Then, linear anodic polarization was carried out in the potentiodynamic mode in the potential range from -250 to $700 \mathrm{mV}$ relative to the corrosion potential $E_{\text {cor }}$ with a sweep rate of $0.16 \mathrm{mV} / \mathrm{s}$ and a polarization curve was obtained from which the corrosion rate was then determined.

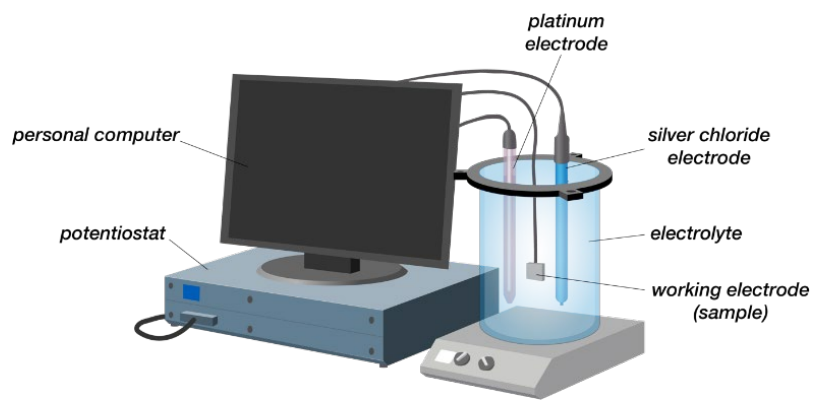

Fig. 1. Electrochemical test cell.

Thermodynamic calculations of phase formation processes during solidification and cooling of steel was calculated using Thermo-Calc Software [11] with the TCFE6 database.

\section{Results and Discussion}

\subsection{Thermodynamic modeling}

The balance of austenite and ferrite in examined DSS depends on the temperature. Fig. 2 shows the results of thermodynamic calculations of phase formation processes. Examined steel crystallize through $\delta$-ferrite, which then undergoes polymorphic transformation into austenite in the solid state. The maximum content of $\delta$-ferrite is reached at the solidus temperature $\left(1400^{\circ} \mathrm{C}\right)$, after which its share decreases rapidly. Already at $1210^{\circ} \mathrm{C}$, an equal amount of austenite and $\delta$-ferrite is achieved in this steel. With a subsequent decrease in temperature, the precipitation of chromium nitrides, $\sigma$-phase and chromium carbides is possible $[8,9]$.

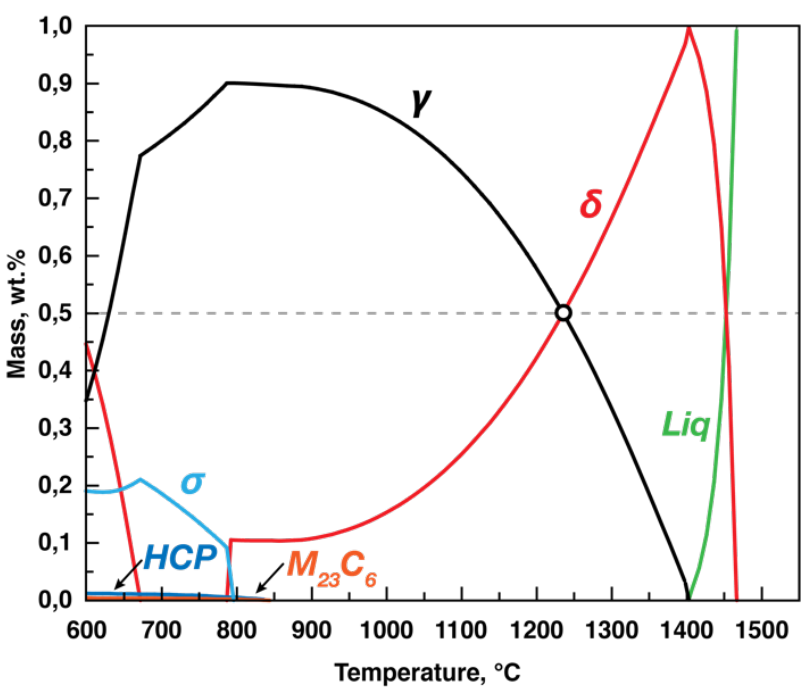

Fig. 2. Thermodynamic calculations for examined steel.

\subsection{Effect of heat treatments on microstructure evolution}

In accordance with the dependences obtained using thermodynamic calculations (Fig. 2), during annealing of samples at temperatures of $1100^{\circ} \mathrm{C}$ and $1200^{\circ} \mathrm{C}$, the number, size and nature of the distribution of phases, which have a decisive effect on the properties of the finished product, are different.

Fig. 3 shows the microstructures in the as-cast and heat-treated at different temperatures. In the as-cast steel contain ferrite (gray), austenite (white), and $\sigma$-phase precipitations (dark).

As-cast sample contains $36 \%$ of $\delta$-ferrite. Part of the ferrite are in the form of massive polygonal regions (Fig. $3, a$ ), which did not have time to undergo transformation during rapid cooling of the casting. In the regions adjacent to these massive grains, small austenite grains are formed, filling the ferrite matrix. Apparently, polymorphic transformation occurs primarily in interdendrite spaces, where the content of austenite stabilizing elements is increased $[12,13]$, and dendrite arms rich in $\delta$-ferrite stabilizing elements don't have time to transform into austenite due to the low diffusion mobility of atoms. Therefore, large grains of supercooled metastable $\delta$-ferrite remain inside them. When heated to $1100^{\circ} \mathrm{C}$, supercooled $\delta$-ferrite, located at the dendrite axes, quickly transforms into austenite [14] with the formation of large austenite regions (Fig. 3, b). Austenite in interdendritic spaces growth and spheroidized by the Ostwald ripening mechanism [15]. In this case, its partial dissolution occurs, and as a result of these two processes, the volume fraction of austenite after annealing at $1100^{\circ} \mathrm{C}$ and quenching remains the same as in as-cast sample. When steel is heated to $1200^{\circ} \mathrm{C}$ (Fig. 3,c) the volume fraction of austenite decreases in accordance with the thermodynamic curve (Fig. 2, a) to $47.5 \%$. The dimensions of the austenite islands [7] continue to increase due to the processes of coarsening of the structure, but their number decreases. 


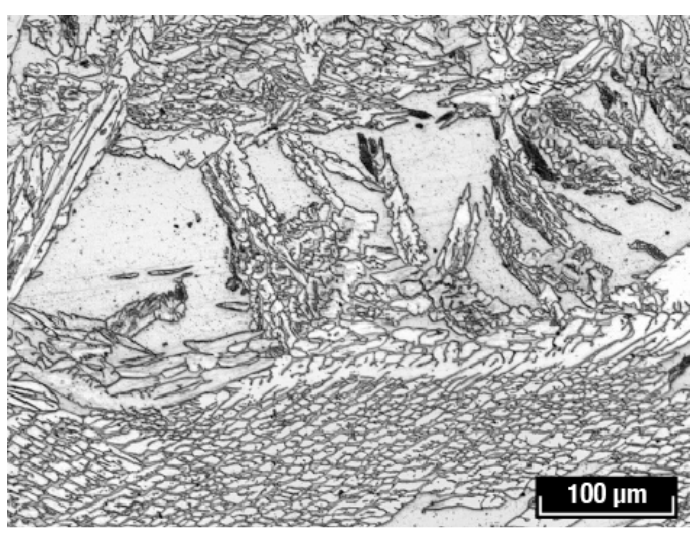

$a$

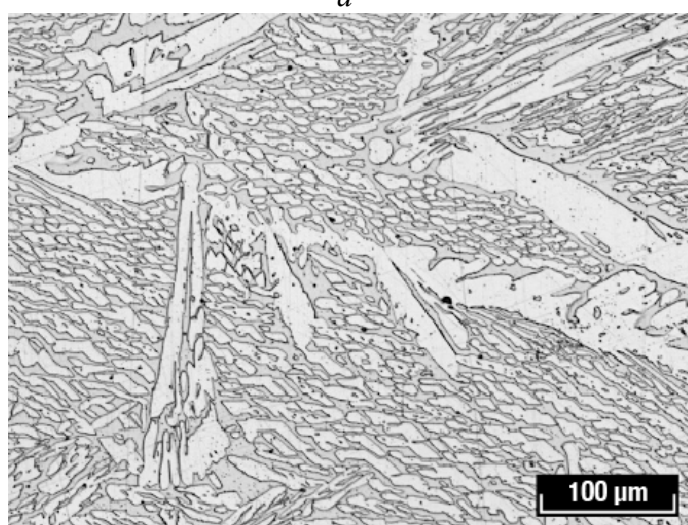

b

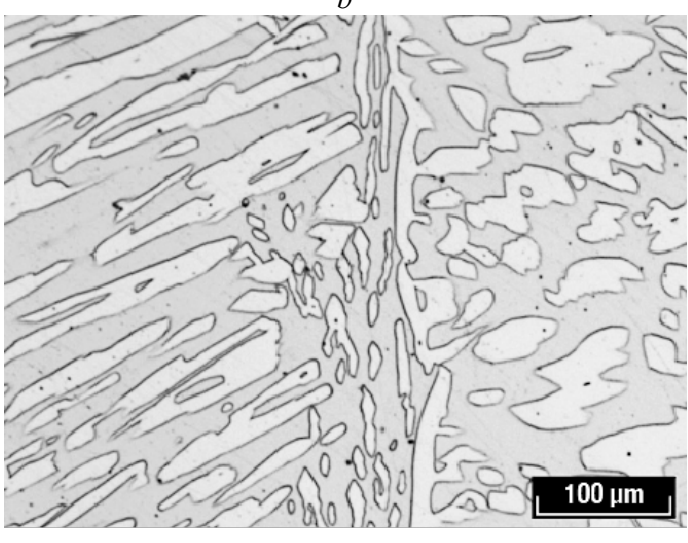

$c$

Fig. 3. The microstructural evolution of samples from as-cast (a) to quenched from $1100^{\circ} \mathrm{C}(b)$ and $1200^{\circ} \mathrm{C}(c)$.

Thus, the evolution of the phase composition of the steel proceeds in full accordance with the forecast obtained by thermodynamic calculations.

\subsection{Electrochemical Studies}

The key consumer property of the steel is the value of pitting potential $\left(E_{\mathrm{pit}}\right)$, which characterizes the steel resistance to pitting corrosion. The pitting resistance equivalent number (PREN) is preliminarily estimated for the material by chemical composition using empirical relationships. PREN is a predictive measurement of a stainless steel's resistance to localized pitting corrosion based on its chemical composition and PREN correlates with the potential for pitting. In this study, to calculate the value of PREN, used the follow equation [16]:

$$
\text { PREN }=(C r-14.5 C)+3.3 M o+2 W+2 C u+16 N
$$

For examined steel the PREN is 24.4.

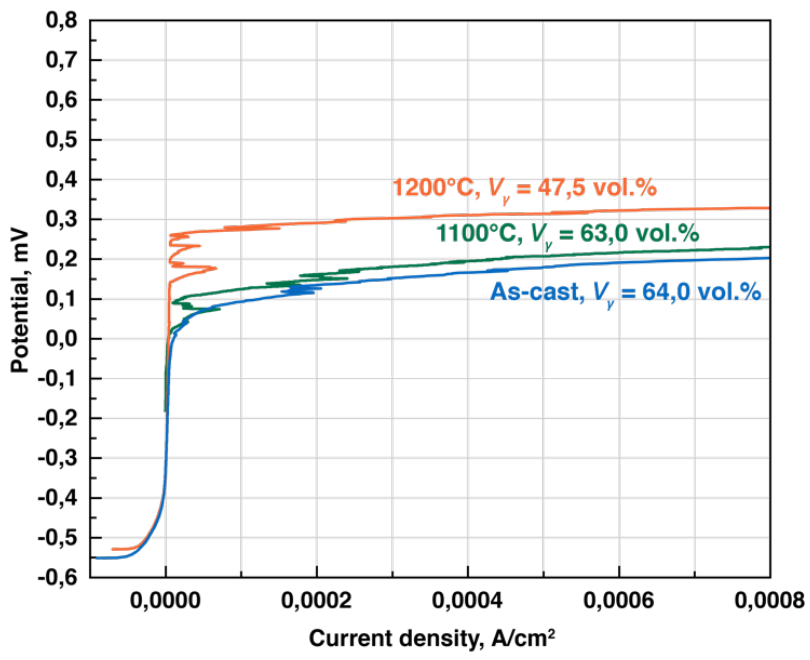

Fig. 4. Potentiodynamic polarization curves for test samples of examined steel.

The analysis of the curves shows that the pitting potential for the sample quenched from $1200^{\circ} \mathrm{C}$ is more positive than the others. This is due to the fact that in this case, as the quenching temperature increases, the ferrite/austenite ratio tends to 50/50. Consequently, the equal ratio of ferrite to austenite in duplex steels ensures their maximum corrosion resistance.

Table 2 summarizes the key results obtained in this work: the pitting potential $\left(E_{\text {pit }}\right)$, the amount of austenite in steel $(V \gamma)$ and the PREN.

Table 2. Results of the study.

\begin{tabular}{|c|c|c|c|}
\hline Sample & $\boldsymbol{E}_{\text {pit }}$ & $\boldsymbol{V} \boldsymbol{\gamma}$, vol.\% & PREN \\
\hline As-cast & 76 & 64.0 & \multirow{2}{*}{24.4} \\
\cline { 1 - 3 } Quenched from $1100^{\circ} \mathrm{C}$ & 110 & 63.0 & \multirow{2}{*}{} \\
\cline { 1 - 3 } Quenched from $1200^{\circ} \mathrm{C}$ & 264 & 47.5 & \\
\hline
\end{tabular}

The amount of austenite in the as-cast practically doesn't change after quenching from $1100^{\circ} \mathrm{C}$, and the improvement of properties is the result of the ongoing homogenization and elimination of the $\sigma$-phase precipitation [5-7]. As the volume fraction of austenite decreases from 64 vol. $\%$ in the as-cast to 47.5 vol. $\%$ after quenching from $1200^{\circ} \mathrm{C}, E_{\text {pit }}$ increases.

Thus, by choosing the optimal annealing and quenching temperature depending on the chemical composition of the steel, an acceptable level of pitting potential in the steel can be achieved.

\section{Conclusions}

The effect of heat treatment on the structure and corrosion properties of lean duplex stainless steel has been examined. Using thermodynamic modeling, the regularities of the evolution of the structure of the examined steel were established and interpreted under different variants of heat treatment. The influence of the 
microstructure on the change in the pitting potential is shown.

\section{References}

1. Practical guidelines for the fabrication of duplex stainless steels, International Molybdenum Association (IMOA), London, UK, pp. 1-64 (2009)

2. Lapechenkov A., Fedorov A., Galata L., Piskarev A., Comparative analysis of corrosion resistance of S31200 duplex stainless steel and its analogue (Materials today: Proceedings, February 2020)

3. Alkhimenko A., Corrosion testing of experimental steels for oilfield pipelines (E3S Web of Conferences, 121, 01001, 2019)

4. ISO 13709:2009 Centrifugal pumps for petroleum, petrochemical and natural gas industries

5. Ran Q., Xu Y., Li J., Wan J., Xiao X., Yu H., Jiang L., Effect of heat treatment on transformationinduced plasticity of economical Cr19 duplex stainless steel (Materials \& Design (1980-2015), Volume 56, pp. 959-965, 2014)

6. Zhang W., Hu J., Effect of annealing temperature on transformation induced plasticity effect of a lean duplex stainless steel (Materials Characterization, 79, pp. 37-42, 2013)

7. Calliari I., Zanesco M., Bassani P., Ramous E. Analysis of secondary phases precipitation in duplex stainless steels (2009)

8. Kazakov, A.A., Zhitenev, A.I., Fedorov, A.S., Fomina, O.V., Forecasting the perspective compositions of duplex stainless steels (Izvestiya Ferrous Metallurgy, Volume 63, Issue 3-4, pp. 254260, 2020)

9. ISO 17475:2005 Corrosion of metals and alloys Electrochemical test methods — Guidelines for conducting potentiostatic and potentiodynamic polarization measurements, Technical Committee: ISO/TC 156 Corrosion of metals and alloys

10. Kovalev M., Alkhimenko A., Shakhmatov A. Electrochemical studies of welded joints corrosion resistance made from stainless steels (Materials today: Proceedings, 2020)

11. Andersson J.O., Helander T., Höglund L., Shi P.F., and Sundman B. Thermo-Calc and DICTRA, Computational tools for materials science (Calphad, 26.2, 273-312, 2002)

12. Kazakov A.A., Oryshchenko, A.S., Fomina, O.V., Zhitenev, A.I., Vikhareva, T.V., Controlling behavior of $\delta$-ferrite in nitrogen-containing chromium-nickel-manganese steels (Inorganic Materials: Applied Research, Volume 8, Issue 6, pp. 817-826, November 2017)

13. Gooch, T.G. Corrosion Resistance of Welds in Duplex Stainless Steels, 91 (1991)

14. Cvijović Z.T. Precipitation behavior of faster solidified duplex stainless steel (Conference paper.
Proc $8^{\text {th }}$ ECS and Image Analysis, September 4-7, Bordeaux, France, 2001)

15. Lifshitz, I.M.; Slyozov, V.V. The Kinetics of Precipitation from Supersaturated Solid Solutions (Journal of Physics and Chemistry of Solids, 19 (12): 35-50, 1961)

16. Garfias-Mesias L. F. The Effect of Microstructure on the Pitting Resistance of Duplex Stainless Steels (January 2015 NACE - International Corrosion Conference Series 2015) 